\begin{tabular}{|l|l|l||}
\hline \multicolumn{2}{|c|}{ PublisherInfo } \\
\hline \hline PublisherName & $:$ & BioMed Central \\
\hline \hline PublisherLocation & $:$ & London \\
\hline \hline PublisherImprintName & $:$ & BioMed Central \\
\hline \hline
\end{tabular}

\title{
Centenarian genes
}

\begin{tabular}{|l|l|l||}
\hline \multicolumn{2}{|c|}{ ArticleInfo } \\
\hline \hline ArticleID & $:$ & 3892 \\
\hline \hline ArticleDOI & $:$ & $10.1186 /$ gb-2001-2-11-reports0039 \\
\hline \hline ArticleCitationID & $:$ & reports0039 \\
\hline \hline ArticleSequenceNumber & $:$ & 17 \\
\hline \hline ArticleCategory & $:$ & Paper report \\
\hline \hline ArticleFirstPage & $:$ & 1 \\
\hline \hline ArticleLastPage & $:$ & 4 \\
\hline \hline & & RegistrationDate : 2001-9-6 \\
ArticleHistory & $:$ & Received \\
\hline ArticleCopyright & $:$ & BioMed Central Ltd2001 \\
\hline \hline ArticleGrants & $:$ & \\
\hline \hline
\end{tabular}




\begin{tabular}{|l|l|l|}
\hline ArticleContext & $:$ & 13059221111 \\
\hline
\end{tabular}

Norman A Johnson

\section{Abstract}

Variation in a region of chromosome 4 may contribute to the probability of living to age 100.

\section{Significance and context}

Why do some people appear to age faster than others do? What influence do genes have on aging? Answers to these difficult questions of universal interest are slowly appearing. Studies of twins demonstrate that the broad-sense heritability of overall longevity is around 0.25 ; that is, $25 \%$ of the variance in this trait is attributed to genetics. Geneticists have identified some genetic variants associated with susceptibility to the major diseases that limit longevity. For instance, individuals who carry the $e-4$ allele of the Apo-E lipoprotein gene are substantially more likely to develop both heart disease and Alzheimer's disease.

Thomas Perls and his colleagues have taken a somewhat different tack to studying aging in humans, focusing on people who have extraordinary longevity. They hypothesize that these very long-lived people represent a special class of people who not only largely escape the main age-related diseases (cancer, cardiovascular disease, stroke and diabetes) but who also age more slowly than the general population. Perls' team found that siblings of centenarians are four times as likely to live to age 91 as the general population. They are now interested in more specific genetic analysis. Few centenarians have the disease-associated genetic variants such as $e-4$ of Apo-E, but do they also have specific genetic differences that predispose them to longer lives, apart from the relative absence of deleterious alleles? Is it the genetic variants they have or the variants they do not have that allows for their extreme longevity?

\section{Key results}

Puca et al. performed a genome-wide scan for chromosomal regions associated with longevity. Their sample consisted of 137 sibships containing 308 individuals. In each of these sibships, at least one of the members (the proband) attained a minimum age of 98 . In addition to the proband, each sibship had at least one other female aged 95 or greater or one male aged 91 or greater. The participants in the study were from North America and consisted of many different ethnic groups. Initially, 400 markers were screened, corresponding to an average density of one marker every 10 centimorgans. Additional markers were screened in regions suggestive of linkage. Their analysis is somewhat different from the standard 
analysis used in other types of mapping studies because only individuals that have the trait (longevity) are included. The researchers performed an 'Affected-only non-parametric analysis', in which they looked for chromosomal regions that showed excess sharing of variants that were identical by descent in the sibships.

The combination of the genome-wide scan and additional finer-scale mapping revealed highly suggestive linkage between extraordinary longevity and a marker on chromosome 4 . On the basis of simulations, the authors concluded that the probability of getting their results if there were no actual linkage between the trait and the marker is 0.044 . With this simulation approach, Puca et al. bypassed the problem of determining significance levels when performing multiple comparisons. Other tests confirmed the significance level.

\section{Reporter's comments}

Studies like those of Puca et al. should be considered as places to start rather than endpoints. It is clear that genetic variation for a propensity to exceptional longevity exists. Although tantalizingly suggestive, the mapping results of the present paper are not conclusive. The sample size is relatively modest and the significance values for the mapping to the region on chromosome 4 are marginal ( $p$ approximately 0.04). Moreover, that region of chromosome could harbor many genes involved in longevity. It should also be mentioned that suggestive linkages were found for several other regions of the genome. We do not know yet how simple or complex the genetic architecture of exceptional longevity is. The authors are aware of the need for further study and note: "Additional association studies with these families and replication of these results with an independent data set should facilitatethe positional cloning of a gene that influences the ability toage well and achieve exceptional longevity". These results may eventually lead to a better understanding of the molecular processes involved in aging and may suggest ways by which the aging process can be slowed.

\section{Table of links}




\section{References}

1. Puca AA, Daly MJ, Brewster SJ, Matise TC, Barrett J, Shea-Drinkwater M, Kang S, Joyce E, Nicoli J, Benson E: A genome-wide scan for linkage to human exceptional longevity identifies a locus on chromosome 4. Proc Natl Acad Sci U S A. 2001, 98: 10505-10508. 0027-8424

This PDF file was created after publication. 